\title{
A Prospective Observational Study of Return to Work after Single Level Lumbar Discectomy
}

\author{
Suk-Hyung Kang, ${ }^{1}$ Jin Seo Yang, ${ }^{1}$ Steve Sungwon Cho, ${ }^{2}$ Yong-Jun Cho, Jin Pyeong Jeon, ${ }^{1}$ Hyuk Jai Choi ${ }^{1}$ \\ Department of Neurosurgery, Chuncheon Sacred Heart Hospital, Hallym University Medical Center, Hallym University College of Medicine, \\ Chuncheon, Korea \\ The Barrow Neurological Institute, ${ }^{2}$ Phoenix, AZ, USA
}

Objective : Lumbar disc herniation (LDH) is a common disease, and lumbar discectomy (LD) is a common neurosurgical procedure. However, there is little previous data on return to work (RTW) after LD. This study investigated the period until the RTW after LD prospectively. Clinically, the pain state at the time of RTW also checked. RTW failure rate 6 months after surgery also investigated.

Methods : Patients with daily/regular jobs undergoing LD between September 2014 and December 2018 were enrolled. Pain was assessed by the Oswestri Disability Index (ODI) and the Numeric Rate Scale (NRS). Employment type was divided into self-employed, regular and contracted. Monthly telephone interviews were conducted to check RTW status and self-estimated work capability after surgery.

Results : Sixty-seven patients enrolled in this study. Three patients failed to RTW, and three others resigned within 6 months after surgery. The preoperative NRS and ODI were $7.2 \pm 1.2$ and $22.1 \pm 7.9$, respectively. The average time to RTW was $5.1 \pm 6.0$ weeks. At RTW, NRS was 1.5 \pm 1.8 and ODI was 6.3 \pm 3.9 . Amongst patients that successfully returned to work were 16 self-employed workers, 42 regular employees, and three contracted workers. The time to RTW of self-employed, regular, and contracted workers were 5.9 \pm 8.8 , $4.2 \pm 4.3$ and $13.3 \pm 2.3$ weeks, respectively $(p=0.011)$. Thirty-six of the patients that returned to work self-reported a $22.8 \pm 15.6 \%$ reduction in work capability at 6 months.

Conclusion : RTW may vary depending on the employment status. In this study, we found that while employment type may affect the length to RTW, most patients were able to RTW and $>40 \%$ of patients reported no loss of work capabilities 6 months postoperatively, hopefully alleviating some patient hesitation towards LD.

Key Words : Lumbar · Diskectomy · Return to work · Loss of work capability · Patient reported outcome measures.

\section{INTRODUCTION}

Lumbar disc herniation (LDH) and lumbar stenosis are common spinal pathologies. While lumbar stenosis is more common in the elderly, LDH often affects the younger population and is thus, more associated with loss of productivity in

- Received : August 6, 2020 •Revised : September 9, 2020 •Accepted : September 19, 2020

- Address for reprints : Suk-Hyung Kang

Department of Neurosurgery, Chuncheon Sacred Heart Hospital, Hallym University Medical Center, Hallym University college of Medicine, 77 Sakju-ro, Chuncheon 24253, Korea

Tel : +82-33-240-5173, Fax : +82-33-242-9970, E-mail : nscharisma@hanmail.net, ORCID : https://orcid.org/0000-0002-1130-9754

This is an Open Access article distributed under the terms of the Creative Commons Attribution Non-Commercial License (http://creativecommons.org/licenses/by-nc/4.0) which permits unrestricted non-commercial use, distribution, and reproduction in any medium, provided the original work is properly cited. 
the socio-economic aspect.

Hence, the medical community has examined different aspects of LDH and lumbar discectomies, the primary surgical treatment for $\mathrm{LDH}^{8}$. Epidemiologic trends including incidence, demographic factors and different surgical approaches have been delved into but have shown relatively small changes during the last decade ${ }^{9}$. Surgical results, infection rates and recurrence rates are also commonly studied ${ }^{2,16,18)}$. For many surgeons, the focus has been on reducing LDH recurrence rates and postoperative infection rates.

However, little has been studied regarding the loss of work capability after LDH. There are no reports on the loss of work capability after conservative treatments for LDH and scant studies on post-discectomy loss of work capability. The evaluation of loss of work capability after lumbar discectomy is very difficult and complex due to the numerous intertwining factors that affect the opportunity cost of lumbar discectomies.

Furthermore, the patients undergoing lumbar discectomies and their employers want clear answers about how long the patient would need sick leave and whether the patient could return to their previous job. Of course, these questions are also very difficult to answer because there are many variables and unexpected complications.

Overall, the complication rate of microdiscectomies is $10.8 \%{ }^{177}$. Nerve root injury, surgical error, durotomy, hemato$\mathrm{ma}$, wound complication, recurrent herniation and reoperation were reported as complications after lumbar disc surgery. In contrast, the success rate after lumbar disc surgery is about $80 \%(63-96 \%)^{5)}$. Assuming that patients without postoperative complications have had successful discectomies, we should further study these patients in order to better understand the socio-economic effects of lumbar discectomies.

This study is a prospective observational study of how long it takes for the patients who undergo single segment lumbar discectomies without complications to return to work (RTW). We also investigated the overall rate of patients returning to work and recorded their clinical evaluations at the time of RTW. In addition, this study examined how employment type is related to the RTW period as a social factor.

\section{MATERIALS AND METHODS}

This study was approved by the Institutional Ethics Review
Board of Chuncheon Sacred Heart Hospital, Hallym University Medical Center (CHUNCHEON 2014-01-003). This study investigated the RTW in patients without complications after lumbar discectomies. Thus, factors and complications that may adversely affect the surgical results were excluded. This study also focused on patients with regular jobs, so that we could document the RTW status. Surgical indications were for patients who were diagnosed with $\mathrm{LDH}$ on magnetic resonance imaging (MRI) and did not respond to conservative treatment for at least 6 weeks. All patients underwent surgery with one of three spinal surgeons at our institution. The operations were performed using microscopic discectomy techniques. The patients were discharged 3 days after surgery began outpatient follow-up 2 weeks after surgery.

Inclusion criteria : patients with regular jobs who underwent surgical treatment for single-segment LDH between September 2014 and December 2018. Exclusion criteria : patients with previous discectomies at other levels or instrumentations, including dynamic fixation or motion segment preservation. Patients with recurrent disc herniation at the same level after discectomy, multilevel discectomies, postoperative infections, postoperative hematomas, or severe neurologic deficits at presentation, such as cauda equina syndrome. Patients who suffered trauma after the discectomy, such as mild traumatic brain injury, falls, and compression fractures. Patients with spondylolysis and spondylolisthesis. Patients lost to follow-up or unable to interview by phone.

Preoperatively, the sex and age of the patients were recorded for demographic analysis. The degree of pain at presentation and prior to surgery was assessed by the Oswestri Disability Index (ODI) and the Numeric Rate Scale (NRS). Preoperative muscle strength was measured using the Royal Medical Research Council of Great strength grading scale. We evaluated disc degeneration at the surgical level and at the most degenerated level using the Pfirrmann grade on the $\mathrm{MRI}^{7}$. The degree to which the nerve roots were compressed by the herniated disc was measured from 1 (minimum) to 5 (most severe) according to Kang et al.'s report ${ }^{10,11)}$.

Postoperatively, outpatient or telephone interviews were conducted at 1-month intervals. At the time of each interview, pain assessments were conducted using the ODI and the NRS. For the socioeconomic evaluation, the type of employment was divided into self-employed, regular employee, and contracted employee. If a patient could not RTW within 6 
months, the patient was judged to have failed to RTW. Patients who could perform telephone interviews after returning to work were also asked to self-evaluate the degree of loss of their own work capability at 6,12 , and 18 months after surgery.

The duration of hospital stays and weeks until RTW were measured. The period until RTW, the pain at RTW, and the failure rate to RTW were compared by employment type.

\section{RESULTS}

This study was a prospective observational study in a single institution. The authors performed 850 spinal surgeries from September 2014 to December 2018. Among them, 401 were microdiscectomies for $\mathrm{LDH}$, and 84 patients were eligible for this study. Their average age was $43.3 \pm 9.4$ years, with mean age $44.1 \pm 1.0$ years for males $(n=68)$ and $40.1 \pm 3.0$ years for females $(n=16)$. Seventeen cases were removed from analysis due to lack of follow-up, infection, or re-operation, and 67 patients remained in our final analysis (Fig. 1).

Of the 67 patients analyzed, there were 54 males and $13 \mathrm{fe}$ males. The average age was $42.5 \pm 9.3$ years. During the 6 months after surgery, three patients failed to RTW, and three others resigned after 4 weeks, 9 weeks, and 3 months of returning to work, respectively. The six patients who could not RTW were two accommodation workers, one self-employer of a restaurant, one regular desk worker, one truck driver and one construction worker.

Sixty-one patients (51 males and 10 females) successfully returned to work after lumbar discectomy. The mean age of these patients was $42.0 \pm 8.2$ years. Clinically, the preoperative average symptom duration was $10.6 \pm 26.2$ weeks. The preoperative NRS and ODI were $7.2 \pm 1.2$ and $22.7 \pm 7.9$, respectively. Mean postoperative hospital stay was $3.6 \pm 0.9$ days, and the final outpatient follow-up period was $76.7 \pm 76.4$ days. The time to RTW was $5.1 \pm 6.0$ weeks. At the time of RTW, NRS was 1.5 \pm 1.8 and ODI was $6.3 \pm 3$.9. NRS at the last follow-up was $0.6 \pm$

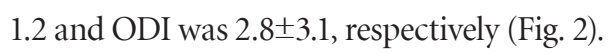

There were no clinical, radiological or insurance differences between males and females except NRS when they returned to work (Table 1).

Amongst the patients that returned to work, there were 16 self-employed workers, 42 regular employees and three contract workers. The time to RTW of self-employed, regular and

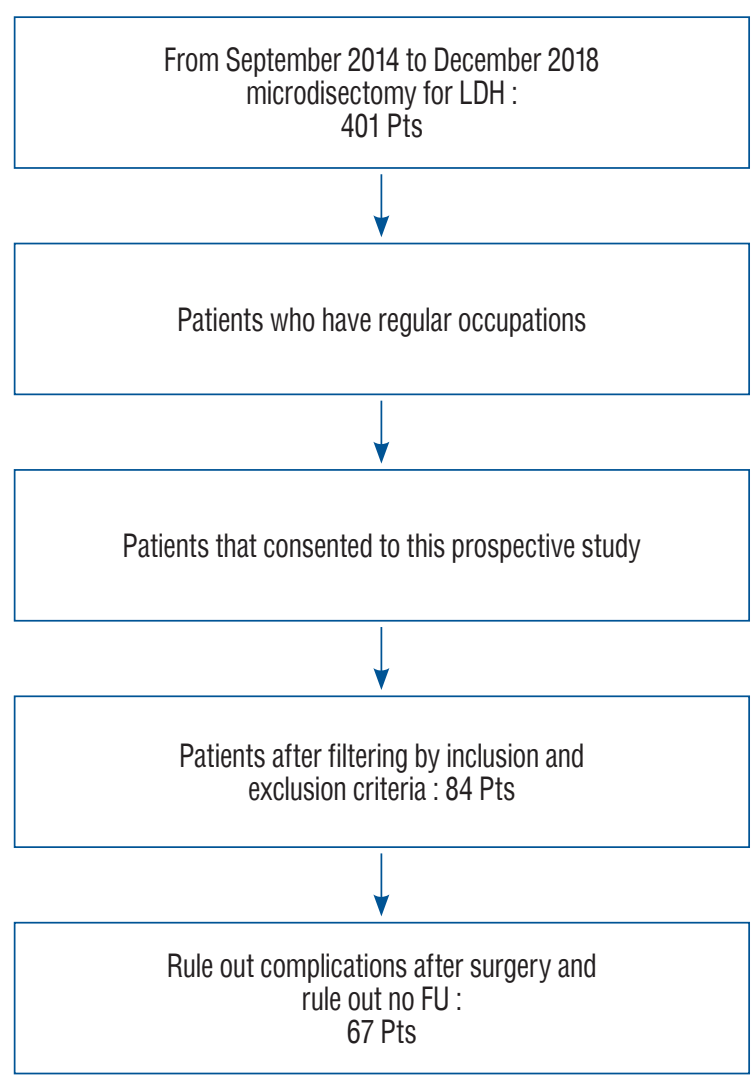

Fig. 1. Flow chart and enrolled patients in this prospective observational cohort study. LDH : lumbar disc herniation, Pts : patients, FU : follow-up.

contract workers were $5.9 \pm 8.8,4.2 \pm 4.3$, and $13.3 \pm 2.3$ weeks, respectively (analysis of variance, $p=0.030$ ).

At the time of RTW, the ODI was $6.8 \pm 3.6$ for the self-employed, $6.5 \pm 3.9$ for full-time workers and $1.0 \pm 1.7$ for contract workers $(p=0.049)$ (Table 2).

The 61 patients also self-estimated the loss of their work capabilities at 6,12 , and 18 months after the discectomies. Twenty-five patients reported no loss of labor force 6 months after discectomy. The other 36 reported reductions in productivity at 6 months postoperatively. They estimated that they had lost $22.8 \pm 15.6 \%$ of their work capability compared to the preoperative baseline. No one changed jobs or positions after RTW.

Factors potentially associated with loss of work productivity after RTW were assessed. There were no differences in clinical factors, including preoperative pain severity, preoperative motor weakness, and surgical outcomes. There were also no differences in employment status, insurance type and time to RTW. There were no statistical differences in MRI findings, such as root compression and Pffirmann grade of disc degen- 


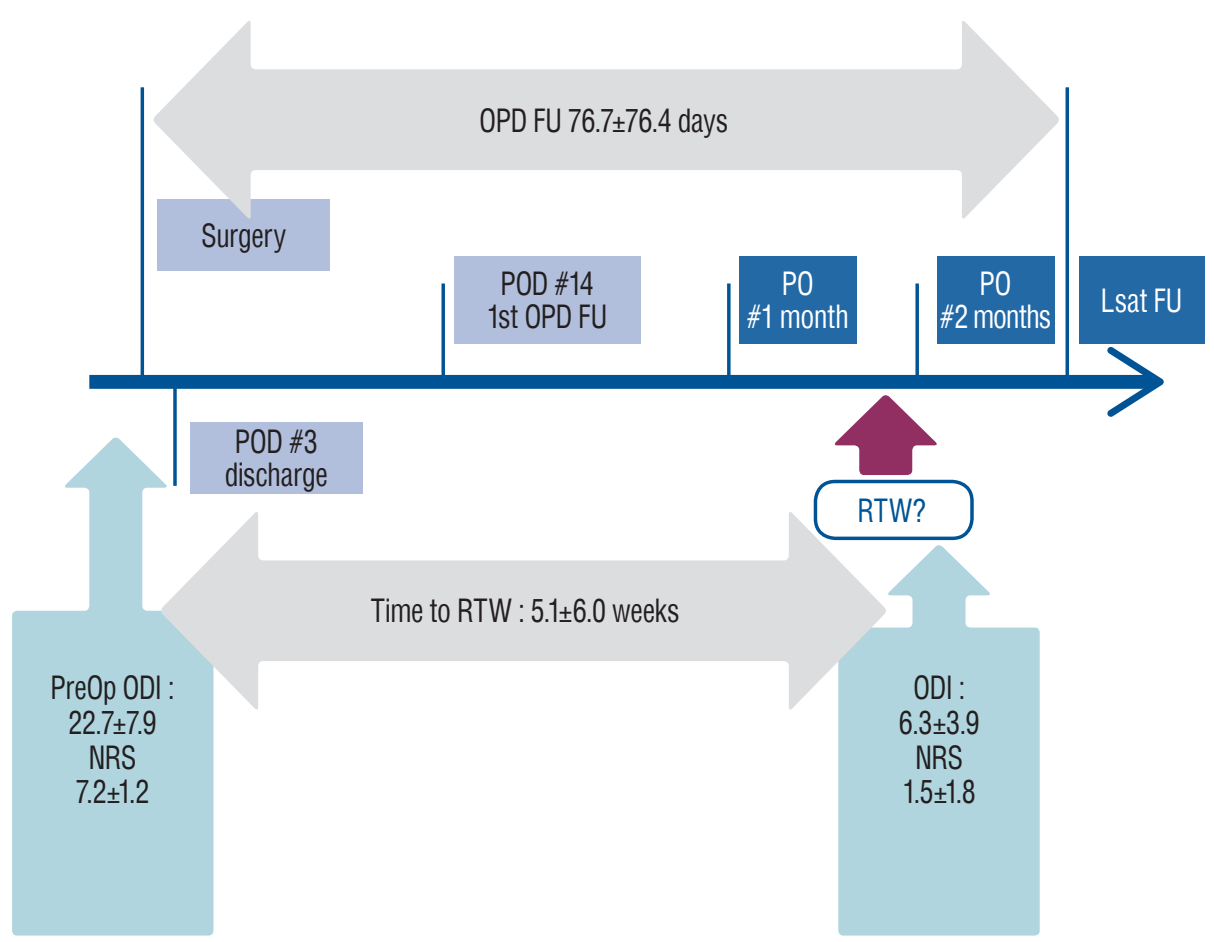

Fig. 2. Schematic of clinical result and time to return to work after single-segment lumbar discectomy. OPD : outpatients department, FU : follow-up, POD : post operation days, PreOp : pre-operation, ODI : Oswestri Disability Index, NRS : Numeric Rate Scale, RTW : return to work.

Table 1. Comparison of clinical factors, insurance and employment status between male and female

\begin{tabular}{|c|c|c|c|}
\hline Clinical factor & Male $(n=51)$ & Female $(n=10)$ & $p$-value \\
\hline Age (years) & $42.8 \pm 7.1$ & $38.0 \pm 11.9$ & 0.251 \\
\hline Pre OP symptom period (weeks) & $10.6 \pm 28.0$ & $10.7 \pm 14.6$ & 0.992 \\
\hline Pre OP ODI & $22.9 \pm 8.0$ & $21.9 \pm 8.0$ & 0.728 \\
\hline Pre OP NRS & $7.2 \pm 1.2$ & $6.8 \pm 1.0$ & 0.313 \\
\hline Post OP hospital stay (days) & $3.7 \pm 0.9$ & $3.4 \pm 0.7$ & 0.432 \\
\hline OPD FU (days) & $71.6 \pm 72.0$ & $102.6 \pm 95.7$ & 0.244 \\
\hline Time to RTW & $5.1 \pm 6.5$ & $5.0 \pm 2.8$ & 0.948 \\
\hline RTW ODI & $5.9 \pm 3.7$ & $8.0 \pm 4.4$ & 0.121 \\
\hline RTW NRS & $1.3 \pm 1.6$ & $2.5 \pm 2.3$ & 0.044 \\
\hline Last ODI & $3.0 \pm 3.2$ & $2.0 \pm 2.4$ & 0.363 \\
\hline Last NRS & $0.6 \pm 1.2$ & $0.4 \pm 0.8$ & 0.575 \\
\hline Insurance type, NHI : MA : IAI & $49: 1: 1$ & $10: 0: 0$ & $0.817^{*}$ \\
\hline Employment state, SE : RW : CW & $16: 32: 3$ & $0: 10: 0$ & $0.067^{*}$ \\
\hline
\end{tabular}

Values are presented as mean \pm standard deviation unless otherwise indicated. *Chi-square results. OP : operation, ODI : Oswestri Disability Index, NRS : Numeric Rate Scale, OPD : outpatients department, FU : follow-up, RTW : return to work, NHI : national health insurrance, MA : medical aid, IAI : industrial accident insurrance, SE : self-employe, RW : regular worker, CW : contract worker

eration (Table 3).

The self-estimated loss of work productivity changed over time. The number of patients that reported no loss of produc- tivity increased from 25 at 6 months to 29 at 12 months, and then to 34 at 18 months after surgery. Overall, the self-estimated loss of productivity decreased over time (Table 4 and Fig. 3 ). 
Table 2. Clinical result and time to return to work after lumbar discectomy according to employment type

\begin{tabular}{|c|c|c|c|c|c|c|c|c|c|c|c|}
\hline Employment state & Age & $\begin{array}{l}\text { Pre Sx. } \\
\text { period } \\
\text { (weeks) }\end{array}$ & Pre_ODI & Pre_NRS & $\begin{array}{l}\text { Post OP } \\
\text { hospital } \\
\text { stay } \\
\text { (days) }\end{array}$ & $\begin{array}{c}\text { OPD FU } \\
\text { (days) }\end{array}$ & $\begin{array}{c}\text { Time } \\
\text { to RTW } \\
\text { (weeks) }\end{array}$ & $\begin{array}{c}\text { RTW_ } \\
\text { ODI }\end{array}$ & $\begin{array}{c}\text { RTW_- } \\
\text { NRS }\end{array}$ & Last ODI & $\begin{array}{l}\text { Last } \\
\text { NRS }\end{array}$ \\
\hline Self-employed $(n=16)$ & $45.8 \pm 7.3$ & $7.1 \pm 7.0$ & $22.2 \pm 9.0$ & $7.3 \pm 0.8$ & $3.5 \pm 0.8$ & $88.5 \pm 105.5$ & $5.9 \pm 8.8$ & $6.8 \pm 3.6$ & $1.5 \pm 1.5$ & $4.0 \pm 3.8$ & $0.9 \pm 1.5$ \\
\hline Regular worker $(n=42)$ & $40.7 \pm 8.1$ & $11.7 \pm 31.1$ & $22.9 \pm 7.9$ & $7.1 \pm 1.3$ & $3.7 \pm 1.0$ & $74.8 \pm 65.6$ & $4.2 \pm 4.3$ & $6.5 \pm 3.9$ & $1.6 \pm 1.9$ & $2.6 \pm 2.8$ & $0.5 \pm 1.1$ \\
\hline Contract worker $(n=3)$ & $39.7 \pm 10.3$ & $14.0 \pm 15.6$ & $22.0 \pm 2.0$ & $6.3 \pm 0.6$ & $3.0 \pm 0.0$ & $39.3 \pm 0.6$ & $13.3 \pm 2.3$ & $1.0 \pm 1.7$ & $0.0 \pm 0.0$ & $0.0 \pm 0.0$ & $0.0 \pm 0.0$ \\
\hline Total & $42.0 \pm 8.2$ & $10.6 \pm 26.2$ & $22.7 \pm 7.9$ & $7.2 \pm 1.2$ & $3.6 \pm 0.9$ & $76.7 \pm 76.4$ & $5.1 \pm 6.0$ & $6.3 \pm 3.9$ & $1.5 \pm 1.8$ & $2.8 \pm 3.1$ & $0.6 \pm 1.2$ \\
\hline$p$-value (ANOVA) & 0.087 & 0.815 & 0.948 & 0.426 & 0.383 & 0.578 & 0.030 & 0.049 & 0.335 & 0.076 & 0.398 \\
\hline
\end{tabular}

Values are presented as mean \pm standard deviation. Sx. : Symptom, ODI : Oswestri Disability Index, NRS : Numeric Rate Scale, OP : operation, OPD : outpatients department, FU : follow-up, RTW : return to work, ANOVA : analysis of variance

Table 3. Comparison of clinical factors between those reporting no loss of work productivity and those reporting a loss at 6 months after lumbar discectomy

\begin{tabular}{lccc}
\hline Clinical factor & No loss $(\mathbf{n}=\mathbf{2 5})$ & Yes loss $(\mathbf{n}=\mathbf{3 6})$ & $\boldsymbol{p}$-value \\
\hline Age (years) & $41.1 \pm 9.6$ & $42.6 \pm 7.1$ & 0.505 \\
Male : female & $19: 6$ & $32: 4$ & $0.181^{*}$ \\
Pre OP symptom period & $7.7 \pm 10.4$ & $12.7 \pm 33.1$ & 0.469 \\
Pre OP ODI & $22.4 \pm 8.5$ & $22.9 \pm 7.6$ & 0.779 \\
Pre OP NRS & $7.0 \pm 1.3$ & $7.2 \pm 1.1$ & 0.558 \\
Post OP hospital stay (days) & $3.5 \pm 0.7$ & $3.7 \pm 1.0$ & 0.536 \\
OPD FU (days) & $63.9 \pm 70.4$ & $85.6 \pm 80.0$ & 0.280 \\
Time to RTW & $4.8 \pm 5.6$ & $5.3 \pm 6.3$ & 0.735 \\
RTW ODI & $5.4 \pm 3.7$ & $6.9 \pm 3.9$ & 0.148 \\
RTW NRS & $1.3 \pm 1.7$ & $1.6 \pm 1.8$ & 0.571 \\
Insurance type, NHI : MA : IAI & $25: 0: 0$ & $34: 1: 1$ & $0.488^{*}$ \\
Employment state, SE : RW : CW & $9: 16: 0$ & $7: 26: 3$ & $0.152^{*}$ \\
\hline
\end{tabular}

Values are presented as mean \pm standard deviation unless otherwise indicated. ${ }^{*}$ Chi-square results. OP : operation, ODI : Oswestri Disability Index, NRS : Numeric Rate Scale, OPD : outpatients department, FU : follow-up, RTW : return to work, NHI : national health insurrance, MA : medical aid, IAI : industrial accident insurrance, SE : self-employe, RW : regular worker, CW : contract worker

\section{DISCUSSION}

The objective of this study was to determine the economic implications of surgical treatment of LDHs. The study included 67 patients in a prospective observational study conducted at a single institution. The patients returned to work at an average of 5.4 weeks after single-level lumbar discectomies. Six of 67 patients $(9.0 \%)$ were unable to RTW within 6 months following surgery. Six months after surgery, 25 out of 67 (41.0\%) reported no loss of work capability, while 36 reported some loss of work capability.

In reviewing the literature, there are very few studies on
RTW after spinal surgery compared to other topics. The timeframe to RTW after spinal surgery is necessary data, but it is difficult to investigate properly and researchers are generally less interested in the topic. Instead, they are more interested in the surgical results and complications than in assessing when patients RTW. A few studies have investigated the duration of sick leave prior to RTW in patients after lumbar discectomies, but interestingly, the results vary widely depending on the country of origin.

In our South Korean study, the patients returned to work 5.4 weeks after lumbar discectomies. In contrast, a Denmark paper on RTW after lumbar discectomy reported different re- 
Table 4. Chronologic change of self-estimated loss of work capability after single segment lumbar discectomy

\begin{tabular}{lccc}
\hline & $\begin{array}{c}\text { Self -estimated loss of work } \\
\text { capability at } \mathbf{6} \text { months after } \\
\text { discectomy }\end{array}$ & $\begin{array}{c}\text { Self -estimated loss of work } \\
\text { capability at 12 months after } \\
\text { discectomy }\end{array}$ & $\begin{array}{c}\text { Self -estimated loss of work } \\
\text { capability at 18 months after } \\
\text { discectomy }\end{array}$ \\
\hline Number of No Loss group & $25(41.0 \%)$ & $29(47.5 \%)$ & $34(55.7 \%)$ \\
Number of Yes Loss group & 36 & 32 & 27 \\
\% of self-estimated loss of work capability & $22.8 \pm 15.6$ & $18.8 \pm 12.1$ & $17.8 \pm 10.8$ \\
\hline
\end{tabular}

Values are presented as mean \pm standard deviation or number (\%)

\section{Workforce improvement}

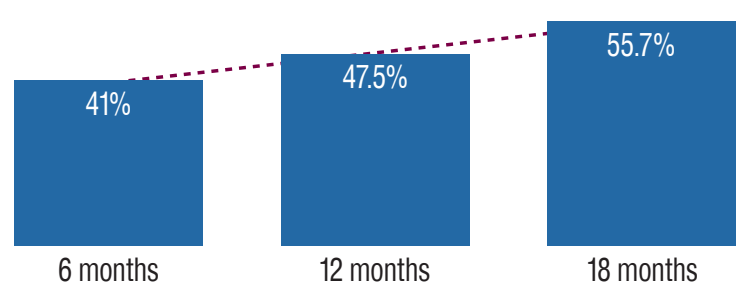

Fig. 3. Chronologic ratio changes of "No loss of workforce" after singlesegment lumbar discectomy. Among 61 patients $41 \%$ of patients selfreported no loss of workforce at 6 months after surgery. This percentage is more improved into $47.5 \%$ and $55.7 \%$ at 12 and 18 months, respectively.

sults. The authors investigated RTW in 351 patients, of whom $62 \%$ returned to work within 2 years after lumbar discectomy ${ }^{19)}$. The study reported that sustained RTW was associated with high education level, positive expectation towards future labor market attachment, preoperative stable labor market attachment, preoperative higher physical quality of life, and less disability.

On the other hand, a German group demonstrated that the type of employment affects the RTW after lumbar discectomies $^{1)}$. In this study of 511 patients, the mean time to RTW was 10.5 weeks. Self-employed people returned to work in 5.4 weeks, civil servants in 10.2 weeks, and regular employees in 14 weeks. While the duration differs from our data, their results demonstrated similar findings to our own, that RTW is associated with the patients' social status.

Finally, a Turkish military doctor reported that about 6 weeks is required before patients can RTW ${ }^{4}$. Others have reported good-to-excellent clinical results in nearly $90 \%$ of patients after lumbar discectomy, with the majority returning to work within 1 month $^{12)}$.

Different social security systems across countries may explain some of the variations in the patients' ability or willingness to RTW after lumbar discectomies. For instance, Schade et al. ${ }^{15)}$, reported that RTW was not influenced by any clinical findings or MR-identified morphological alterations, but rather, depended solely on psychological factors (i.e., depression) and psychological aspects of work (i.e., occupational mental stress). Interestingly, there are some reports that longer sick leaves are negative predictors of patients' RTW. Silverplats et al. ${ }^{18)}$, reported that patients taking sick leaves longer than three months showed a lower RTW rate than those who took less than 2 months of sick leave after lumbar discectomies.

Other studies have investigated factors related to RTW. There have been reports of longer labor loss periods in patients with clinically persistent symptoms 2 months after surgery. Puolakka et al. ${ }^{13)}$ reported that ODI $>20$, leg pain, and poor motivation to work were risk factors for extension of work disability. Furthermore, newer minimally invasive discectomies led to shorter hospital stays and earlier RTW compared to microdiscectomy or open discectomy ${ }^{14}$. In terms of postoperative rehabilitation, $10.1 \%$ of patients who received rehabilitation did not have RTW, compared to $18.1 \%$ of the control group that did not undergo postoperative rehabilitation ${ }^{6}$. Operative techniques and postoperative rehabilitation may be more interesting for surgeons performing lumbar discectomy because these factors can be modulated to affect postoperative outcomes.

Finally, lumbar discectomies may affect the patients' systemic health. Bosković et al. ${ }^{3)}$ reported that the quality of life and mental health values after lumbar microdiscectomies, as measured by the SF36-PHYS domain improved from 25.7 at the beginning of the study to 46.4 over the following 6 months. Likewise, in our study, we found that the self-estimated loss of work productivity gradually improved over 18 months after surgery. This information is important to patients and should be communicated to dispel some of the concerns regarding lumbar discectomies (Table 4 and Fig. 3).

A limitation of this study is the small number of enrolled 
patients. Because personal information related to occupation is the content of the study, there were many patients who could not be enrolled in the study, and many patients refused to be enrolled in the study. In addition, some patients were excluded due to complications such as infection. It would be nice if more subjects were enrolled, but the results are not expected to make a significant difference.

Specifically, the number of contract workers was relatively small compared to other employment statuses. Despite the small sample size, we were able to demonstrate that it seems to take contract workers longer to RTW, at 13.3 weeks ( $p=0.030$ ). Contract workers also reported better ODI when they returned to work ( $p=0.049$ ) (Table 2).

Perhaps, in the case of contract workers, they may not want to reveal their employment status and refused to participate in the research because of their employment type. Or they may have already decided to stop working before surgery. There is a possibility that contract workers could not get a job for longer periods compared to other groups after surgery according to their job. An employer who knows that a contract employee has undergone surgery may have advised him to work again after the workforce is recovered. We think these results are evidence that the employment of contract workers is unstable compared to other groups regardless of the disease.

Six patients were unable to return to work or quit work within 6 months. We did an investigation into the jobs of those six people. However, we have not investigated whether the six quit work for personal reasons or if they quit work due to a loss of workforce due to surgery. It is another one of the limitations of this study.

Overall, this study provides valuable data in demonstrating that patients' employment status may affect their ability to return to work successfully after lumbar discectomies. Although the sample size was small, we believe the results of this study should be considered when surgeons discuss potential surgical outcomes with patients.

\section{CONCLUSION}

Lumbar discectomy is associated with loss of work productivity. In this study, six of 67 patients (8.95\%) did not return to work, about 5 weeks of sick leave were required after single segment lumbar discectomies. The length of sick leave after lumbar discectomy is associated non-clinical factors (i.e., employment state). Loss of work capability occurred after lumbar discectomies; however, more than $40 \%$ of patients reported no productivity loss 6 months after surgery.

\section{CONFLICTS OF INTEREST}

No potential conflict of interest relevant to this article was reported.

\section{INFORMED CONSENT}

Informed consent was obtained from all individual participants included in this study.

\section{AUTHOR CONTRIBUTIONS}

\author{
Conceptualization : SHK, YJC \\ Data curation : SHK, YJC, JSY \\ Formal analysis : SHK, YJC \\ Funding acquisition : YJC \\ Methodology : SHK, JPJ, HJC \\ Project administration : $\mathrm{SHK}$ \\ Visualization : SHK \\ Writing - original draft : SHK \\ Writing - review \& editing : SSC
}

\section{ORCID}

$\begin{array}{ll}\text { Suk-Hyung Kang } & \text { https://orcid.org/0000-0002-1130-9754 } \\ \text { Jin Seo Yang } & \text { https://orcid.org/0000-0003-4883-7224 } \\ \text { Steve Sungwon Cho https://orcid.org/0000-0002-1511-2596 } \\ \text { Yong-Jun Cho } & \text { https://orcid.org/0000-0003-3412-5330 } \\ \text { Jin Pyeong Jeon } & \text { https://orcid.org/0000-0001-8543-6855 } \\ \text { Hyuk Jai Choi } & \text { https://orcid.org/0000-0002-3774-5941 }\end{array}$

\section{- Acknowledgements}

This study was supported by BioGreen21 Program (PJ01121401) of Rural Development Administration of ROK. 


\section{References}

1. Baltzer AW, Schulitz KP : Effect of social status on occupational reintegration after lumbar discotomy. Z Orthop Ihre Grenzgeb 135 : 381385, 1997

2. Beack JY, Chun HJ, Bak KH, Choi KS, Bae IS, Kim KD : Risk factors of secondary lumbar discectomy of a herniated lumbar disc after lumbar discectomy. J Korean Neurosurg Soc 62 : 586-593, 2019

3. Bosković K, Cigić T, Grajić M, Todorović-Tomasević S, Knezević A : The quality of life of patients after a lumbar microdiscectomy: a four-year monitoring study. Clin Neurol Neurosurg 112 : 557-562, 2010

4. Celik $H$, Derincek $A$, Arslanoglu A : Interlaminar discectomy in lumbar disc herniation: shorten postoperative return to work period in recruits undergoing military training. Mil Med 173 : 924-926, 2008

5. Dohrmann GJ, Mansour N : Long-term results of various operations for lumbar disc herniation: analysis of over 39,000 patients. Med Princ Pract 24 : 285-290, 2015

6. Donceel $\mathrm{P}, \mathrm{Du}$ Bois $\mathrm{M}$, Lahaye $\mathrm{D}$ : Return to work after surgery for lumbar disc herniation. A rehabilitation-oriented approach in insurance medicine. Spine (Phila Pa 1976) 24 : 872-876, 1999

7. Griffith JF, Wang YX, Antonio GE, Choi KC, Yu A, Ahuja AT, et al. : Modified pfirrmann grading system for lumbar intervertebral disc degeneration. Spine (Phila Pa 1976) 32 : E708-E712, 2007

8. Jordan J, Konstantinou K, O'Dowd J : Herniated lumbar disc. BMJ Clin Evid 2011 : 1118, 2011

9. Jung JM, Lee SU, Hyun SJ, Kim KJ, Jahng TA, Oh CW, et al. : Trends in incidence and treatment of herniated lumbar disc in Republic of Korea : a nationwide database study. J Korean Neurosurg Soc 63 : 108-118, 2020

10. Kang SH, Choi SH, Seong NJ, Ko JM, Cho ES, Ko KP : Comparative study of lumbar magnetic resonance imaging and myelography in young sol- diers with herniated lumbar disc. J Korean Neurosurg Soc 48 : 501 505, 2010

11. Kang SH, Yang JS, Cho YJ, Park SW, Ko KP : Military rank and the symptoms of lumbar disc herniation in young Korean soldiers. World Neurosurg 82 : e9-e14, 2014

12. Koebbe CJ, Maroon JC, Abla A, El-Kadi H, Bost J : Lumbar microdiscectomy: a historical perspective and current technical considerations. Neurosurg Focus 13 : E3, 2002

13. Puolakka K, Ylinen J, Neva MH, Kautiainen H, Häkkinen A : Risk factors for back pain-related loss of working time after surgery for lumbar disc herniation: a 5-year follow-up study. Eur Spine J 17 : 386-392, 2008

14. Rasouli MR, Rahimi-Movaghar V, Shokraneh F, Moradi-Lakeh M, Chou $R$ : Minimally invasive discectomy versus microdiscectomy/open discectomy for symptomatic lumbar disc herniation. Cochrane Database Syst Rev (9) : CD010328, 2014

15. Schade V, Semmer N, Main CJ, Hora J, Boos N : The impact of clinical, morphological, psychosocial and work-related factors on the outcome of lumbar discectomy. Pain 80 : 239-249, 1999

16. Schoenfeld AJ, Weiner BK : Treatment of lumbar disc herniation: evidence-based practice. Int J Gen Med 3 : 209-214, 2010

17. Shriver MF, Xie JJ, Tye EY, Rosenbaum BP, Kshettry VR, Benzel EC, et al. : Lumbar microdiscectomy complication rates: a systematic review and meta-analysis. Neurosurg Focus 39 : E6, 2015

18. Silverplats $K$, Lind B, Zoëga B, Halldin K, Rutberg L, Gellerstedt $M$, et al. : Clinical factors of importance for outcome after lumbar disc herniation surgery: long-term follow-up. Eur Spine J 19 : 1459-1467, 2010

19. Ziegler DS, Jensen RK, Thomsen GF, Carreon L, Andersen MO : Returning to work within two years after first-time, single-level, simple lumbar discectomy: a multifactorial, predictive model. J Occup Rehabil 30 : 274-287, 2020 